\title{
Aplicação de métodos isotópicos e numéricos em paleoceanografia com base em foraminíferos planctônicos
}

\author{
Geise de Santana dos Anjos Zerfass \\ BPA/PDEXP/Cenpes/Petrobras, Cidade Universitária, Ilha do \\ Fundão, Rio de Janeiro. \\ geise_anjos@hotmail.com \\ Francisco Javier Sierro Sánchez \\ Grupo de Geociencias Oceánicas, Facultad de Ciencias, Univ. \\ de Salamanca, Plaza de la Merced s/n, Salamanca, Espanha. \\ Farid Chemale Jr. \\ Núcleo de Geologia, Univ. Federal de Sergipe, Jardim Rosa \\ Elze, Aracaju.
}

\begin{abstract}
APPLICATION OF ISOTOPIC AND NUMERICAL METHODS IN PALEOCEANOGRAPHY BASED ON PLANKTONIC FORAMINIFERA. Paleoceanography represents a multidisciplinary approach that combines efforts to reconstruct the history of oceans and the effects of interactions between changes in the composition, circulation and productivity in large water masses and climate changes. Paleoceanography is a discipline that tries to learn from the past in order to predict future climate changes. In this context, planktonic foraminifera, which are abundant and widely distributed in the oceans, store in their shells past water mass conditions. Age, temperature and productivity are among the parameters that can be inferred by studying the association and the composition of the shells of these organisms. This work is aimed to present the application of isotopic methods and numerical paleoceanography using planktonic foraminifera as a tool. Citation: Zerfass G.S. A., Sánchez F.J.S., Chemale jr. F., 2011. Aplicação de métodos isotópicos e numéricos em paleoceanografia com base em foraminíferos planctônicos. Terræ Didatica, 7(1):4-17<http://www.ige.unicamp.br/terraedidatica/>
\end{abstract}

\section{KEYWORDS Planktonic foraminifera, isotopes, modern analog technique}

\begin{abstract}
RESUMO A paleoceanografia representa uma abordagem multidisciplinar que reúne esforços no intuito de reconstruir a história dos oceanos pretéritos e os efeitos das interações entre as variações na composição, circulação e produtividade nas grandes massas d'água e as mudanças climáticas. Além do interesse pelo passado, a paleoceanografia assume um caráter vanguardista quando se trata de realizar prognósticos de mudanças climáticas futuras. Nesse contexto, os foraminíferos planctônicos, além da sua abundância e ampla distribuição geográfica, armazenam em suas testas a composição das águas onde viveram, registrando as condições físico-químicas das massas d'água. Idade, temperatura e produtividade estão entre os parâmetros que podem ser inferidos por meio do estudo das associações e da composição das carapaças destes organismos. Esse trabalho tem como objetivo apresentar a aplicação de métodos isotópicos e numéricos em paleoceanografia utilizando foraminíferos planctônicos como ferramenta de trabalho.
\end{abstract}

PALAVRAS-CHAVE Foraminíferos planctônicos, Isótopos, Técnica dos análogos modernos

\section{Introdução}

A história dos oceanos está registrada em rochas e fósseis que podem ser analisados com um enfoque multidisciplinar. Devido a isso, o desenvolvimento da paleoceanografia resultou da evolução conceitual e tecnológica de vários ramos do conhecimento, dentre os quais o advento do paradigma da tectô- nica de placas que permitiu novas interpretações paleogeográficas. Da mesma forma, os avanços tecnológicos que possibilitaram a recuperação de sedimentos em águas profundas e a realização de análises químicas cada vez mais precisas de fósseis e sedimentos, foram responsáveis por reconstruções paleoceanográficas detalhadas. 
$\mathrm{Na}$ ciência, a relação entre o objeto de estudo e as ferramentas é determinante na obtenção de resultados de qualidade, o que muitas vezes implica pesquisas em escalas diferentes. No âmbito desta variabilidade de escalas, a micropaleontologia nos fornece um excelente exemplo quando propõe a utilização de testas de foraminíferos planctônicos na reconstrução da circulação oceânica pretérita. Nesse caso, o registro da distribuição dos resquícios de minúsculas formas de vida representa um robusto instrumento para o estudo do deslocamento de massas d'água e nutrientes ao redor do planeta.

Dois tipos de métodos empregando foraminíferos planctônicos são aplicados nos estudos da paleocirculação oceânica: a avaliação da composição isotópica das carapaças e a técnica dos análogos modernos. A composição química (isótopos estáveis e elementos-traço) das testas calcárias fornecem parâmetros para a reconstrução da temperatura e produtividade nos ambientes marinhos antigos.

Os fatores que determinam a composição das assembleias atuais, aplicados à interpretação de assembleias fósseis tais como as técnicas de regressão múltipla, permitem uma estimativa dos parâmetros ambientais pretéritos.

\section{Paleoceanografia e foraminíferos}

Ao longo das últimas décadas tem sido verificado o rápido desenvolvimento da paleoceanografia cujo enfoque é o estudo da história dos oceanos, incluindo a evolução das bacias oceânicas, a produtividade biológica e a dinâmica das correntes (Hay 1988, Wefer et al. 1999).

Uma das principais vertentes dos estudos paleoceanográficos é a avaliação do papel dos processos oceânicos nas mudanças climáticas ao longo da história da Terra. Em tempos de grande inquietação com os efeitos do aquecimento global, muitos estudos têm sido motivados pela necessidade de se compreender o clima durante o Quaternário como um guia para prognósticos de mudanças climáticas futuras.

A paleoceanografia emprega diversos métodos derivados das ciências biológicas e químicas além de técnicas estatísticas para a interpretação de grandes quantidades de dados (Wefer et al. 1999). Os avanços têm se seguido com o desenvolvimento de modelos bidimensionais e tridimensionais baseados em equações conservativas e na aplicação de métodos numéricos como as funções de transferência, por meio das quais é possível transformar a composição de associações fossilíferas em medidas absolutas. Atualmente, o desenvolvimento de modelos paleoceanográficos de alta resolução construídos a partir de extensas bases de dados, têm fornecido dados concernentes à variação temporal de vários fatores que atuaram na circulação dos oceanos pretéritos.

Os foraminíferos planctônicos figuram entre as principais ferramentas utilizadas na paleoceanografia, uma vez que ocorrem desde as águas polares, de ambos os hemisférios, até o Equador, e desde as bacias profundas até as águas das bacias marginais. Além da abundância e da ampla distribuição geográfica, diversas espécies de foraminíferos planctônicos secretam suas testas em equilíbrio com a água do mar, de modo que a composição química das mesmas reflete as características das massas d'água.

\section{Características gerais dos foraminíferos planctônicos}

Os foraminíferos planctônicos fazem parte do grupo dos protistas amebóides marinhos pertencentes ao reino Protoctista, filo Granuloreticulosa, classe Foraminifera, ordem Globigerinida (Loeblich \& Tappan 1992, Sen Gupta 1999). Estes organismos apresentam uma organização celular com organelas típicas de células eucarióticas suplementadas por corpos fibrilares, exclusivos destes organismos (Schiebel \& Hemleben 2005). Fora da testa, o citoplasma se alonga em rizópodos ${ }^{1}$ intercomunicados (Fig. 1), formando uma rede que coleta o alimento (Kucera et al. 2005).

As testas dos foraminíferos planctônicos são compostas por calcita extremamente pura, contendo apenas $1 \%$ em peso de elementos menores e traços tais como magnésio, bário, estrôncio e urânio. As testas são perfuradas e divididas em câmaras e se desenvolvem em estágios (Fig. 1). O estágio inicial consiste de uma primeira câmara esférica denominada prolóculo. A formação da câmara subsequente marca o início do estágio juvenil, quando as câmaras se formam em altas taxas de calcificação. O estágio seguinte, denominado neânico, é marcado por mudanças significativas tanto na morfologia da testa quanto em termos de profundidade do habitat. No estágio adulto a testa está completamente formada, alcançando tamanhos entre $0,1 \mathrm{~mm}$ e $1 \mathrm{~mm}$ (Schiebel \& Hemleben 2005). A abertura

\footnotetext{
${ }^{1}$ Projeções citoplasmáticas anastomosadas utilizadas para fixação, locomoção e captura de alimentos.
} 


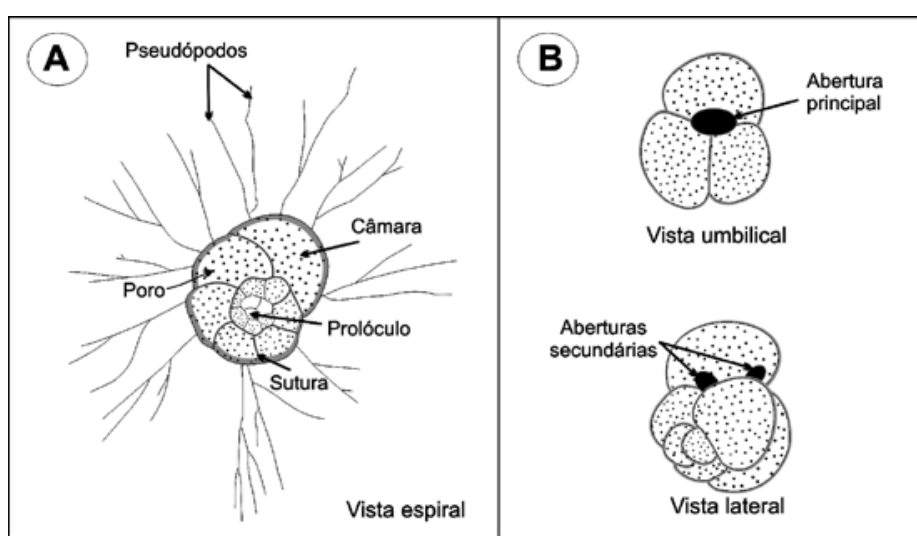
em vista espiral e projeções do citplasma (pseudópodos); B. vistas umbilical e lateral mostrando a posição das aberturas
Figura 1. Morfologia dos foraminíferos. A. Caracteres morfológicos da testa

prosseguiu até o surgimento das formas complexas e especializadas do Cretáceo, formado uma microfauna altamente diversificada. Com a crise do limite Cretáceo-Paleógeno a maioria das espécies de foraminíferos planctônicos desapareceu e, das cinco espécies remanescentes, apenas três (Hedbergella holmdelensis, H. mammouthensis e Guembelitria cretacea) deram origem às formas planctônicas do Cenozoico (Spezzaferri \& Spiegler 2005). As formas modernas evoluíram a partir do Paleoceno quando surgiram as primeiras espécies espinhosas (Schiebel \& Hemleben 2005).

Os foraminíferos planctônicos conecta o organismo com o meio exterior e as câmaras são interconectadas através das aberturas dos estágios prévios. Além da morfologia da testa, a estrutura da parede é um dos caracteres considerados na classificação das espécies (Fig. 2).

Assim como outros grupos de protistas que evoluíram a partir de ancestrais bentônicos com estágio larval planctônico, os foraminíferos planctônicos tiveram origem a partir da evolução de formas bentônicas no Jurássico médio e, por volta do Cretáceo médio, haviam se disseminado por todos os oceanos (Schiebel \& Hemleben 2005, Spezzaferri \& Spiegler 2005).

A evolução dos foraminíferos planctônicos

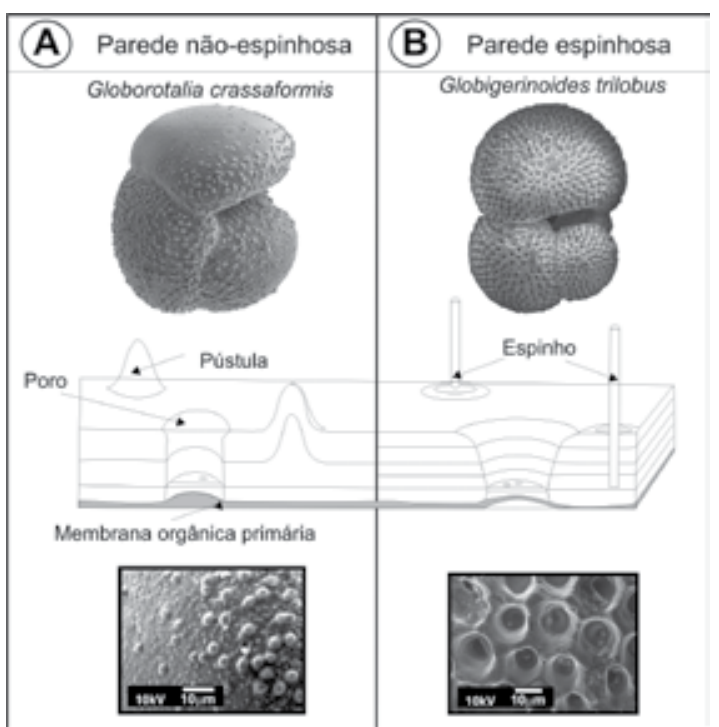

Figura 2. Estrutura da parede da testa. A. parede nãoespinhosa, com pústulas e poros; B. parede espinhosa com estrutura de poros e elevações interporos (modificado de Scheibel \& Hemleben, 2005) habitam oceanos abertos e os mares marginais tais como o Mediterrâneo e o Mar Vermelho, estando ausentes nos mares marginais rasos como o Mar do Norte (Schiebel \& Hembleben 2005). A maioria das espécies vive na superfície e abaixo da termoclina ${ }^{2}$, entretanto, as espécies portadoras de simbiontes ${ }^{3}$, por dependerem da luz, estão restritas à zona eufótica ${ }^{4}$.

A biodiversidade e distribuição horizontal e vertical dos foraminíferos planctônicos atuais são controladas por complexas interações entre parâmetros físicos e químicos, incluindo a concentração de nutrientes, temperatura, salinidade e turbidez da água. Dentre esses fatores, a temperatura da superfície do oceano atua como o principal fator na distribuição latitudinal dos foraminíferos planctônicos (Wade 1964, Scott 1983, Spezzaferri \& Spiegler 2005).

\section{Métodos isotópicos}

Como os elementos químicos que compõem as testas dos foraminíferos são incorporados diretamente a partir da água do mar durante a vida do organismo, a composição das testas reflete a composição da água do mar durante a precipitação do carbonato. Assim, os isótopos entre os quais os de carbono, oxigênio e estrôncio constituem indicadores ambientais e também fornecem um meio de se

${ }_{2}^{2}$ Profundidade na qual ocorre o máximo gradiente de decréscimo de temperatura. Separa a camada superficial do oceano profundo.

${ }^{3}$ Organismo que participa uma relação de vantagem mútua onde dois ou mais organismos de espécies diferentes atuam em conjunto para proveito de ambos. Algumas espécies de foraminíferos hospedam algas unicelulares que auxiliam na sua nutrição produzindo compostos orgânicos.

${ }^{4}$ Região do oceano através da qual a luz penetra, possibilitando aos organismos marinhos a realização da fotossíntese. 
aferir a idade dos fósseis. As testas dos foraminíferos são amplamente utilizadas para a realização de análises isotópicas devido à sua abundância e a fatores metabólicos que condicionam a precipitação do carbonato biogênico em equilíbrio isotópico com a água do mar. A seguir são apresentados os principais métodos que empregam a calcita das testas de foraminíferos em análises isotópicas.

\section{Indicadores de parâmetros ambientais - Proxies}

A composição isotópica de qualquer substância é dada em termos da variação da razão entre diferentes isótopos em comparação com a razão isotópica de uma substância de composição conhecida, sendo apresentada na forma da notação $\delta$ (delta). Uma amostra apresentando $\delta$ positivo representa uma composição enriquecida no isótopo mais pesado, em relação ao padrão, enquanto $\delta=0$ indica que a composição isotópica da amostra é igual a do padrão.

As variações da composição isotópica de carbono e oxigênio estão diretamente relacionadas a mudanças paleoambientais e, devido a isso, representam uma ferramenta para a interpretação de paleoambientes, especialmente na obtenção de parâmetros tais como paleotemperatura, paleoprodutividade, variações do nível do mar.

\section{Isótopos de carbono}

O carbono se constitui na base da vida terrestre, sendo também um dos elementos mais abundantes do universo. Este elemento ocorre na Terra tanto no manto quanto na crosta, além da hidrosfera, biosfera e atmosfera. O carbono ocorre em forma reduzida (compostos orgânicos e carvão), em estado oxidado (dióxido de carbono), como íons carbonato e bicarbonato em solução aquosa e como carbonatos inorgânicos, além de ser encontrado na forma nativa como grafite e diamante (Faure 1986, Hoefs 2009).

Dois isótopos estáveis de carbono ocorrem na natureza, o ${ }^{12} \mathrm{C}$ e o ${ }^{13} \mathrm{C}$. Estes isótopos são fracionados por diversos processos naturais, incluindo a fotossíntese e as reações de troca de isótopos entre compostos de carbono (Fig. 3). A fotossíntese leva ao enriquecimento em ${ }^{12} \mathrm{C}$ dos compostos orgânicos biologicamente sintetizados, uma vez que o ${ }^{12} \mathrm{CO}_{2}$ é preferencialmente utilizado na fotossíntese. Por outro lado, as reações de troca de isótopos entre o $\mathrm{CO}_{2}$ e o carbonato em solução aquosa tendem a enriquecer os carbonatos em ${ }^{13} \mathrm{C}$ (Faure 1986). A composição isotópica do carbono é expressa em termos do parâmetro $\delta^{13} \mathrm{C}$, tendo como padrão de referência o $\mathrm{CO}_{2}$ gasoso obtido das carapaças de belemnites ${ }^{5}$ da Formação Peedee . $^{6}$

\footnotetext{
${ }^{5}$ Exemplares da espécie Belemnitella americana.

${ }^{6}$ Rochas cretácicas aflorantes na planície costeira da porção ocidental do estado da Carolina do Sul e no estado da Carolina do Norte, USA.
}

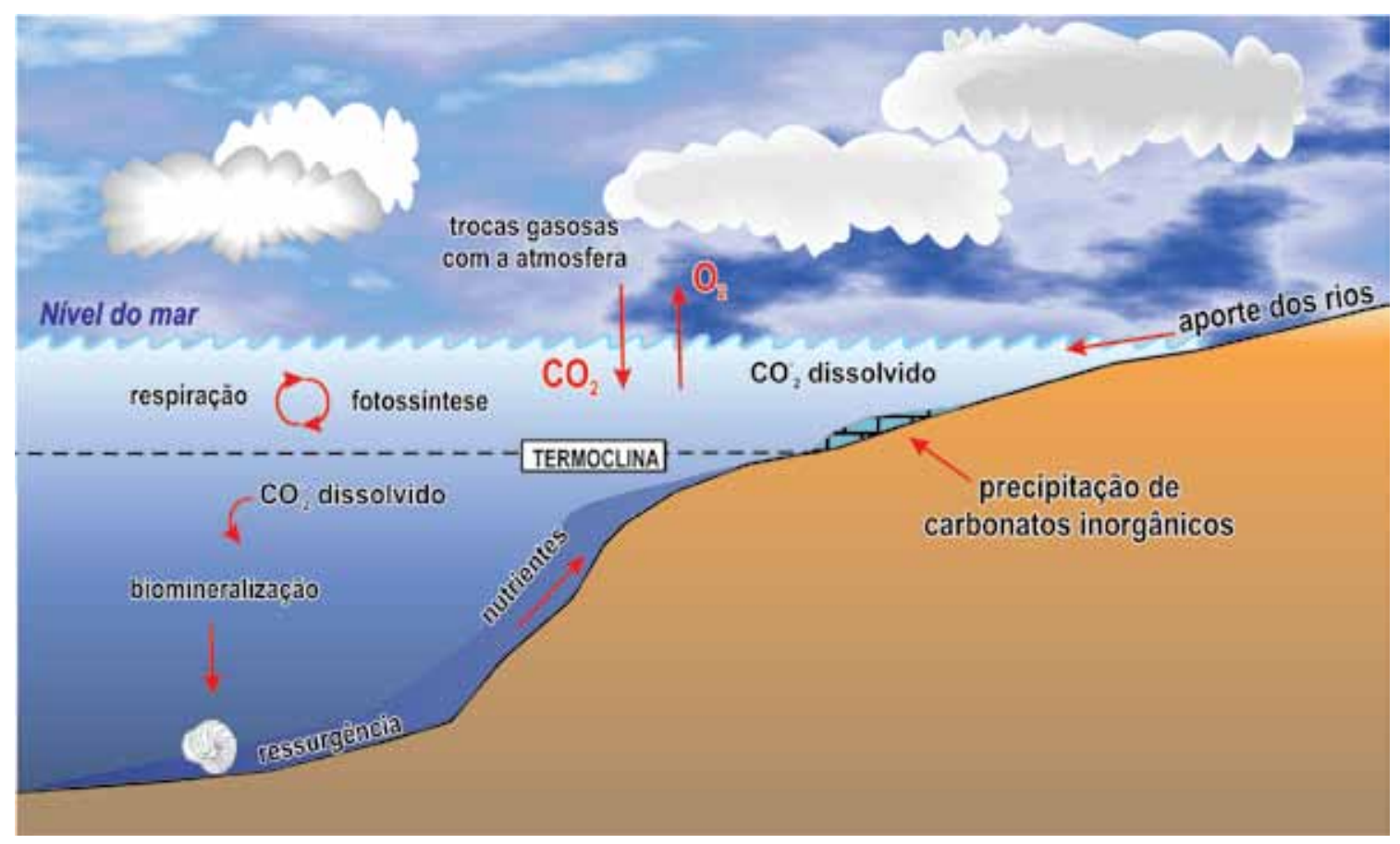

Figura 3. Ciclo dos isótopos do carbono e os principais fatores que afetam a razão isotópica $\delta^{13} \mathrm{C}$ 
$\mathrm{O} \delta^{13} \mathrm{C}$ é expresso pela equação:

$$
\delta^{13} \mathrm{C}=\frac{\left({ }^{13} \mathrm{C} /{ }^{12} \mathrm{C}\right)_{\text {spl }}-\left({ }^{13} \mathrm{C} /{ }^{12} \mathrm{C}\right)_{\text {std }} \times 10^{3}}{\left({ }^{13} \mathrm{C} /{ }^{12} \mathrm{C}\right)_{\text {std }}}
$$

onde $\left({ }^{13} \mathrm{C} /{ }^{12} \mathrm{C}\right)_{\text {std }}$ é a medida do padrão e $\left({ }^{13} \mathrm{C} /{ }^{12} \mathrm{C}\right)$ spl é o valor medido na amostra. Valores positivos de $\delta^{13} \mathrm{C}$ indicam que a amostra é enriquecida $\mathrm{em}{ }^{13} \mathrm{C} \mathrm{em}$ relação ao padrão, enquanto valores negativos implicam depleção de ${ }^{13} \mathrm{C}$ (Faure \& Mensing 2005).

Mudanças na produtividade do fitoplâncton ou na oxidação bacteriana da matéria orgânica na coluna d'água afetam significativamente os valores da razão $\delta^{13} \mathrm{C}$ da água dos oceanos (Mitchell et al. 1996, Wefer et al. 1999). A produtividade do fitoplâncton na água superficial é controlada pelos fluxos de entrada e de saída de nutrientes que são adicionados por meio do aporte fluvial e da reciclagem de nutrientes em águas oceânicas profundas em zonas de ressurgência (Fig. 3) (Wefer et al. 1999). A remoção do isótopo leve do sistema se dá pelo soterramento ou oxidação da matéria orgânica (Scholle \& Arthur 1980), uma vez que o ${ }^{12} \mathrm{C}$ é preferencialmente capturado durante a fotossíntese. Assim, o aumento dos valores de $\delta^{13} \mathrm{C}$ nos carbonatos biogênicos indica um aumento da produtividade. Por outro lado, a intensificação dos processos de retrabalhamento e oxidação da matéria orgânica devolvem ${ }^{12} \mathrm{C}$ ao sistema, diminuindo os valores de $\delta^{13} \mathrm{C}$ (Mitchell et al. 1996, Wefer et al. 1999).

$\mathrm{O} \delta^{13} \mathrm{C}$ médio do oceano é influenciado pelo ciclo global do carbono, mais especificamente pela partição entre oceano, atmosfera e biosfera. Como a fotossíntese utiliza preferencialmente $\mathrm{o}{ }^{12} \mathrm{C}$, a biosfera é um reservatório empobrecido em ${ }^{13} \mathrm{C}$, apresentando valores médios de $\delta^{13} \mathrm{C}$ de $-25 \%$ o (Ravelo \& Hillaire-Marcel 2007).

A composição isotópica de carbono das testas de foraminíferos não reflete a composição do carbono dissolvido na água do mar pois a precipitação biogênica é mais rápida em relação à precipitação inorgânica, resultando em um fracionamento cinético. Os valores de $\delta^{13} \mathrm{C}$ também são influenciados pela fotossíntese dos simbiontes algálicos (Ravelo \& Hillaire-Marcel 2007). Além desses fatores, o efeito vital afeta a composição isotópica de carbono, considerando-se que uma das principais causas do desequilíbrio isotópico é a reincorporação de $\mathrm{CO}_{2}$ metabólico, o qual é isotopicamente mais leve (Erez 1978, Grossman 1987).

\section{Isótopos de oxigênio}

Os isótopos de oxigênio se combinam com os de hidrogênio $\left({ }^{1} \mathrm{He} \mathrm{e}^{2} \mathrm{H}\right)$ para formar água, de modo que a molécula de água pode apresentar diferentes configurações isotópicas, cuja mais comum é ${ }^{1} \mathrm{H}_{2}{ }^{16} \mathrm{O}$ (Faure 1986, Bowen 1988). As moléculas de água mais pesadas terão pressão de vapor menor e, consequentemente, o vapor d'água resultante da evaporação da água líquida é enriquecido nos isótopos mais leves $\left({ }^{16} \mathrm{O}\right.$ e $\left.{ }^{1} \mathrm{H}\right)$. Portanto, a evaporação transfere preferencialmente as moléculas de ${ }^{1} \mathrm{H}_{2}{ }^{16} \mathrm{O}$ para a atmosfera. Da mesma forma, a condensação do vapor d'água em nuvens, produzindo chuva, causa o enriquecimento da fase líquida nos isótopos mais pesados, uma vez que a molécula ${ }^{2} \mathrm{H}_{2}{ }^{18} \mathrm{O}$ passa mais facilmente para a fase líquida devido à sua menor pressão de vapor (Bowen 1988).

O principal fracionamento do oxigênio ocorre durante a precipitação do carbonato e o $\delta^{18} \mathrm{O}$ resultante é fortemente dependente da temperatura, bem como da composição isotópica do meio aquoso no qual a cristalização ocorreu. Se o carbonato é calcita, a temperatura de equilíbrio de cristalização $(t)$ é relacionada como uma função do fracionamento dada por $\delta c=\delta^{18} \mathrm{O}_{\text {calc }}-\delta^{18} \mathrm{O}_{\text {aq }}$, onde os padrões de referência são o PDB (PeeDee Belemnite) para calcita e SMOW (Standard Mean Ocean Water) ${ }^{7}$ para a água (Holser et al. 1996).

Durante os períodos glaciais, quando a água evaporada se precipita em forma de gelo nos continentes em altas latitudes, a remoção preferencial do isótopo mais leve torna a composição isotópica das águas mais enriquecida no isótopo mais pesado, ou seja, os valores de $\delta^{18} \mathrm{O}$ são mais positivos (Ravelo \& Hillaire-Marcel 2007) (Fig. 4).

Em contrapartida, para um mundo livre de capa de gelo (maior parte do Fanerozoico pré-Mioceno), a composição isotópica de oxigênio da água do oceano $\left(\delta^{18} \mathrm{O}_{\mathrm{w}}\right)$ é mais leve, enquanto para um período glacial, é mais pesada do que a do oceano atual. Por definição, a composição isotópica de oxigênio da água do mar atual $\left(\delta^{18} \mathrm{O}_{\mathrm{w}}\right)$ é de $0 \%$ o (SMOW), mas na perspectiva geológica este valor tem sido temporariamente aumentado pela cristalização de uma fração apreciável da massa d água, como o gelo glacial que é muito enriquecido em ${ }^{16} \mathrm{O}$. Por sua vez, os valores da razão isotópica do carbonato $\left(\delta^{18} \mathrm{O}_{c}\right)$ está relacionado não apenas à temperatura mas ambém ao $\delta^{18} \mathrm{O}_{\mathrm{w}}(\mathrm{SMOW})$ da água.

${ }^{7}$ Para converter os valores de SMOW para PDB basta subtrair 0,22\%。. 

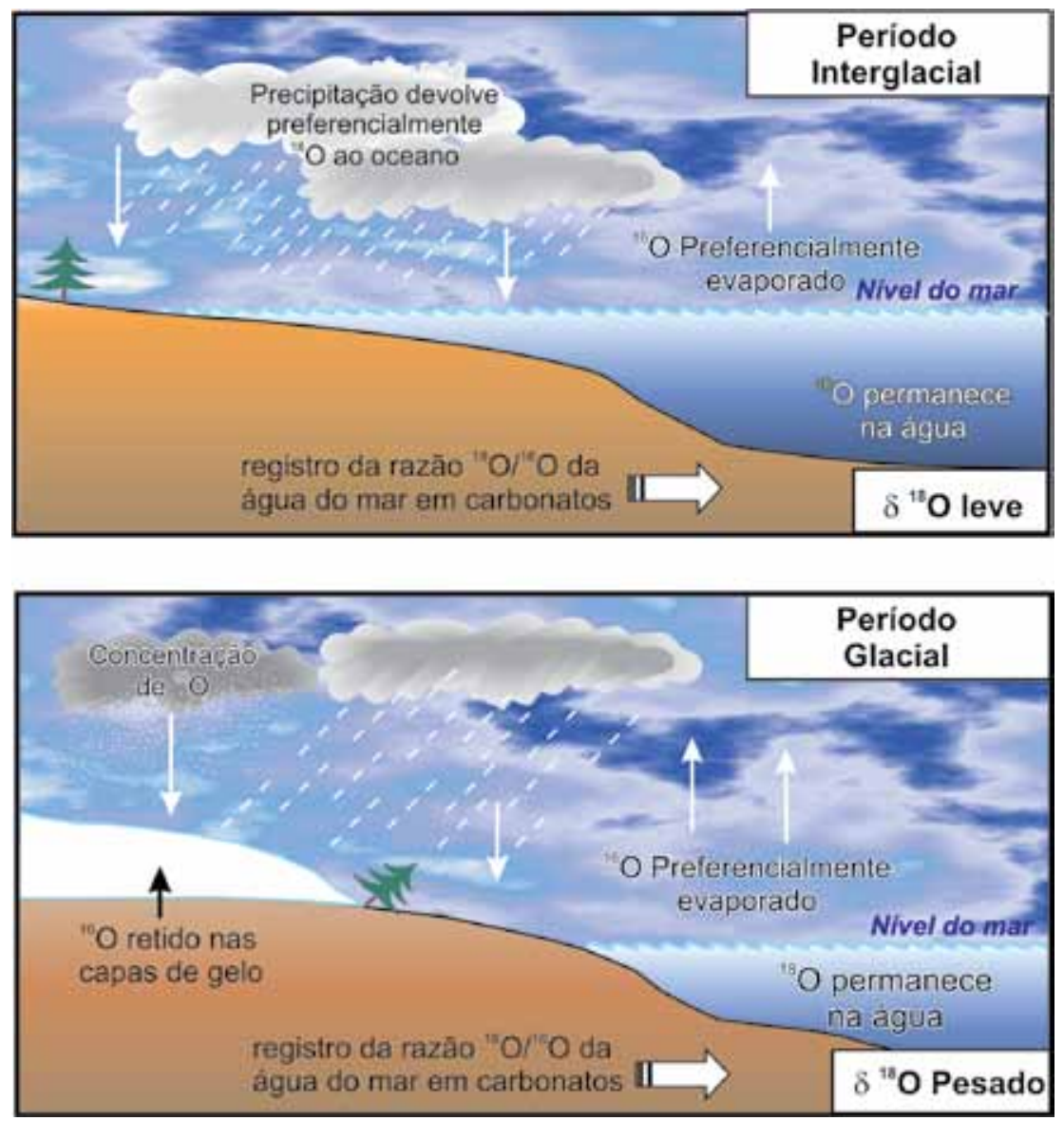

Figura 4. Ciclo dos isótopos de oxigênio mostrando os efeitos da temperatura na composição isotópica dos oceanos

$\delta^{18} \mathrm{O}\left({ }^{\circ} \mathrm{C}\right)=16,0-4,14 \delta_{s}+0,138.2 \Rightarrow \mathrm{T}\left({ }^{\circ} \mathrm{C}\right)=16.0-4.14 \Delta+0.13 \Delta_{*}^{2}$

onde, $\Delta_{c}=(\delta c-\delta \mathrm{w})$, ou seja, é o valor da razão isotópica de oxigênio do carbonato menos o valor da razão isotópica da água que, por definição, representa $\delta \mathrm{w}=0 \%$ o (SMOW).

Em nível regional, a composição isotópica da água do mar varia em função do balanço entre evaporação e precipitação. Durante o processo de evaporação ocorre um fracionamento isotópico que favorece o enriquecimento no isótopo pesado, já que o isótopo leve evapora mais facilmente (Fig. 4). Portanto, os valores isotópicos de oxigênio são altos nas regiões onde o balanço hídrico é negativo em decorrência de intensa evaporação ou porque as precipitações são escassas. Nos cinturões úmidos, em latitudes médias, a precipitação domina sobre a evaporação de modo que a salinidade e os valores isotópicos são baixos. Por sua vez, em baixas latitudes, nas zonas próximas aos grandes desertos, as precipitações são mínimas e a evaporação é muito forte, de modo que a salinidade e os valores isotópicos de oxigênio são altos.
Em nível global, o fracionamento isotópico em função da retração ou da expansão da calota polar causa variações significativas nos valores de $\delta^{18} \mathrm{O}$. Como consequência de uma expansão das calotas polares em períodos glaciais, ocorre a transferência da água do "reservatório oceano" para o "reservatório gelo" e, com isso, o valor composição isotópica média do oceano aumenta. Por outro lado, quando ocorre um degelo, toda a água isotopicamente muito mais leve que estava armazenada na forma de gelo volta ao oceano causando uma queda no valor da composição isotópica do oceano.

Em relação aos fatores que limitam a confiabilidade dos valores de paleotemperatura derivados da razão isotópica de oxigênio está o já mencionado efeito vital (Erez 1978, Grossman 1987). Este efeito pode estar relacionado à atividade fotossintética de simbiontes algálicos ${ }^{8}$, induzindo a um fracionamento cinético que causa depleção em ${ }^{18} \mathrm{O}$ (Ravelo \& Hillaire-Marcel 2007).

Ao se utilizar razões isotópicas de oxigênio para a obtenção de dados de paleotempertura, deve-se levar em consideração a sazonalidade no crescimento da carapaça devido a mudanças de habitat dos organismos durante o seu ciclo de vida, a composição da água e a temperatura de calcificação (Grossman 1987).

Os esforços para calibrar equações de paleotemperatura incluíram experimentos controlando a exposição à luz de foraminíferos planctônicos cultivados em laboratório para determinar os efeitos causados pela atividade fotossintética dos simbiontes além de outros fatores tais como o estágio de desenvolvimento ontogenético e a concentração

\footnotetext{
${ }^{8}$ Algas unicelulares que vivem em simbiose com outros organismos hospedeiros, os quais recebem parte da energia produzida pelos simbiontes através da fotossíntese. Nos foraminíferos planctônicos os principais simbiontes são diatomáceas e crisófitas.
} 
Tabela 1. Equações de paleotemperatura calibradas para diferentes espécies de foraminíferos planctônicos*

\begin{tabular}{l|l|l}
\hline \multicolumn{1}{c|}{ Autor } & \multicolumn{1}{c|}{ Equação } & \multicolumn{1}{c}{ Espécie } \\
\hline Erez \& Luz (1983) & $\mathrm{T}\left({ }^{\circ} \mathrm{C}\right)=17-4,52(\delta \mathrm{c}-\delta \mathrm{w})+0,03(\delta \mathrm{c}-\delta \mathrm{w})^{2}$ & Globigerinoides sacculifer \\
\hline Bouvier-Sourmagnac $(1985)$ & $\mathrm{T}\left({ }^{\circ} \mathrm{C}\right)=16,4-4,67(\delta \mathrm{c}-\delta \mathrm{w})$ & Orbulina universa \\
\hline Bemis et al. (1998) & $\mathrm{T}\left({ }^{\circ} \mathrm{C}\right)=16,5-4,8(\delta \mathrm{c}-\delta \mathrm{w})$ & Orbulina universa \\
\hline Bemis et al. (1998) & $\mathrm{T}\left({ }^{\circ} \mathrm{C}\right)=13,2-4,89(\delta \mathrm{c}-\delta \mathrm{w})$ & $\begin{array}{l}\text { Globigerina bulloides } \\
\text { (espécimes com 12 câmaras) }\end{array}$ \\
\hline
\end{tabular}

^ dados compilados de Bemis et al. (1998)

de carbonato disponível na água. A Tabela 1 mostra algumas equações para o cálculo de paleotemperatura, calibradas para diferentes espécies de foraminíferos planctônicos.

\section{Métodos de datação e correlação}

Em geral, é possível estabelecer com algum grau de confiança se um evento é anterior, contemporâneo ou posterior a outro ocorrido em uma localidade diferente. Entretanto, muitas vezes é necessário precisar a época em que um evento ocorreu, o que torna a obtenção de idades um tema de fundamental importância nas Ciências da Terra.

Uma das chaves para o avanço no conhecimento das mudanças climáticas pretéritas está nas datações. Datar os registros climáticos com a maior precisão possível é de suma importância para correlacionar mudanças paleoceanográficas verificadas em distintos locais do planeta. Os foraminíferos planctônicos são os organismos mais utilizados para a aplicação de métodos de datação direta ou indireta em estudos paleocenográficos, tais como o método do radiocarbono e a correlação com a curva da razão isotópica de estrôncio.

\section{0 método do radiocarbono}

Em 1905, o físico Robert Rutherford sugeriu pela primeira vez a possibilidade de utilizar a radioatividade natural para medir o tempo. Com o avanço do conhecimento, descobriu-se que diversos isótopos radioativos, dentre os quais o ${ }^{14} \mathrm{C}$, podem ser utilizados como geocronômetros uma vez conhecida a constante de desintegração e calculando-se as concentrações do isótopo-pai e do isótopo-filho.

A datação por radiocarbono foi uma das descobertas mais significativas do século XX. O método foi desenvolvido por um grupo de cientistas liderado por Williard Libby, da Universidade de Chicago, que recebeu o Prêmio Nobel de Química de 1960
(Faure \& Mensing 2005). A importância do método reside no fato de que qualquer material que contém carbono apresenta potencial para ser datado por ${ }^{14} \mathrm{C}$ (Hughen 2007).

Além dos isótopos estáveis de carbono também ocorre na natureza o ${ }^{14} \mathrm{C}$ (radioativo), o qual perfaz apenas $0,0000000001 \%$ do total de átomos de carbono. O radiocarbono é um isótopo cosmogênico produzido pela interação da radiação cósmica com o nitrogênio atmosférico na troposfera (Hughen 2007). O radiocarbono possui meia-vida curta, (cerca de 5.730 anos) e teria se esgotado a muitos milhões de anos na Terra se não estivesse sendo constantemente incorporado nas camadas mais altas da atmosfera (Faure \& Mensing 2005).

Uma vez adicionado à atmosfera, $\mathrm{O}^{14} \mathrm{C}$ se incorpora ao ciclo do $\mathrm{CO}_{2}$. Parte do ${ }^{14} \mathrm{CO}_{2}$ é absorvida pelas plantas e organismos fotossintetizantes e parte é dissolvida na água do mar, onde se mistura às águas superficiais e profundas. Embora a produção de ${ }^{14} \mathrm{C}$ varie com a latitude, a mistura relativamente rápida na troposfera resulta em um aporte homogêneo ao oceano (Hughen 2007).

O carbonato de cálcio precipitado em equilíbrio com o $\mathrm{CO}_{2}$ atmosférico também incorpora $\mathrm{O}^{14} \mathrm{C}$ (Faure \& Mensing 2005). As moléculas de ${ }^{14} \mathrm{CO}_{2}$ se misturam com as moléculas de $\mathrm{CO}_{2}$ formadas por átomos de ${ }^{12} \mathrm{C} \mathrm{e}{ }^{13} \mathrm{C}$ e são incorporadas ao ciclo do carbono ao serem assimiladas pelas plantas por meio da fotossíntese (Libby 1970) (Fig. 5). Mais de $95 \%$ do ${ }^{14} \mathrm{C}$ é absorvido nos oceanos como carbonato dissolvido, o qual será utilizado por organismos marinhos tais como corais, moluscos, foraminíferos e nanofósseis calcários para compor seus esqueletos ou carapaças (Walker 2005).

O método de datação por radiocarbono consiste na medição da razão ${ }^{14} \mathrm{C} /{ }^{12} \mathrm{C}$ em materiais como carbonatos biogênicos e restos vegetais. Quanto maior o tempo transcorrido desde a formação desses materiais, menores serão os valores da razão ${ }^{14} \mathrm{C} /{ }^{12} \mathrm{C}$ nas carapaças já que o ${ }^{12} \mathrm{C}$ é estável e o ${ }^{14} \mathrm{C}$ se desintegra. Outros materiais datáveis por este 


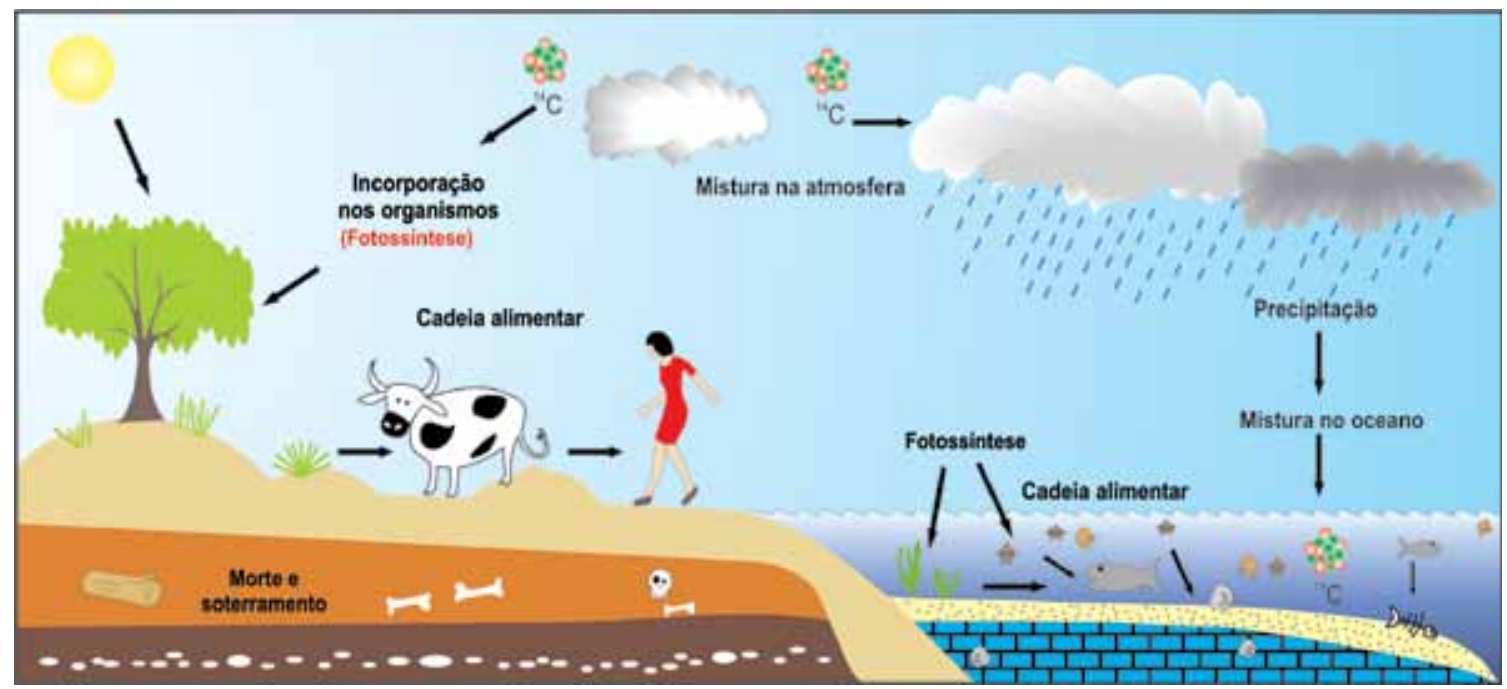

Figura 5. Ciclo do ${ }^{14} \mathrm{C}$ e materiais datáveis pelo método do radiocarbono

método são coprólitos ${ }^{9}$, couro, espeleotemas ${ }^{10}$ e solos. Todos estes materiais possuem átomos de carbono em moléculas que foram sintetizadas por organismos marinhos ou terrestres.

A datação por radiocarbono tem servido como ferramenta para a datação acurada do registro marinho dos últimos 50.000 anos. Entretanto, alterações diagenéticas ${ }^{11}$ nos carbonatos podem resultar em cronologias não confiáveis para idades mais antigas do que 35.000 anos (Hughen 2007).

\section{0 método da razão isotópica ${ }^{87} \mathrm{Sr} /{ }^{86} \mathrm{Sr}$}

O estrôncio é um elemento químico do grupo dos metais alcalinos terrosos que substitui o cálcio em alguns minerais como a apatita e a calcita (Faure 1986). Este elemento apresenta quatro isótopos, ${ }^{84} \mathrm{Sr},{ }^{86} \mathrm{Sr},{ }^{87} \mathrm{Sr}$ e ${ }^{88} \mathrm{Sr}$, dos quais o mais abundante é o ${ }^{88} \mathrm{Sr}$ com $82,53 \%$, e o menos abundante é o ${ }^{84} \mathrm{Sr}$, totalizando apenas $0,56 \%$ do total de átomos de estrôncio. Apenas o ${ }^{87} \mathrm{Sr}$ é radiogênico e tem origem no decaimento radioativo do ${ }^{87} \mathrm{Rb}$ pela emissão de uma partícula $B$.

Os principais fatores que determinam a concentração de estrôncio nos oceanos são o fluxo dos rios, especialmente aqueles que erodem rochas ígneas ou metamórficas e a incorporação por meio de processos hidrotermais nas cadeias mesoceânicas (Holser

\footnotetext{
${ }^{9}$ Fezes fossilizadas. Sua importância reside no fato de que podem indicar 0 tipo de dieta de espécies extintas.

${ }^{10}$ Concreções carbonáticas formadas no interior de cavernas tanto nas paredes quanto no teto.

${ }^{11}$ Alterações na composição e/ou estrutura dos sedimentos e fósseis devidas a processos que ocorrem após a deposição tais como a dissolução e a recristalização.
}

et al. 1996) (Fig. 6). Os produtos da erosão continental fornecem razões ${ }^{87} \mathrm{Sr} /{ }^{86} \mathrm{Sr}$ mais altas $(\sim 0,7180)$, enquanto as trocas hidrotermais fornecem razões mais baixas ( $\sim 0,7030)$ (Katz et al. 2010).

$\mathrm{O}$ estrôncio é retirado da água dos oceanos por meio da precipitação de carbonatos e fosfatos e, como não há fracionamento durante a cristalização, estes minerais representam amostras diretas da concentração deste elemento na água do mar (Holser et al. 1996).

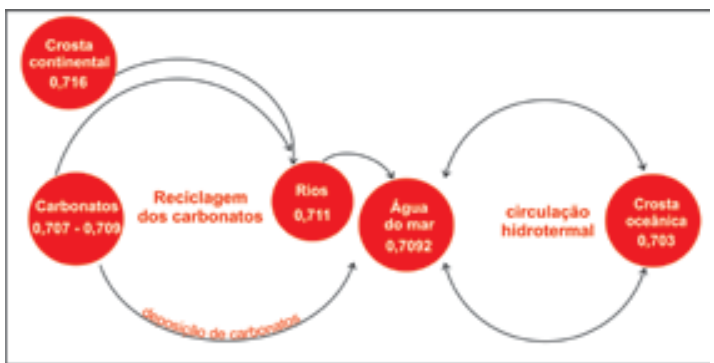

Figura 6. Fontes de isótopos de estrôncio para os oceanos e taxas médias da razão isotópica ${ }^{87} \mathrm{Sr} /{ }^{86} \mathrm{Sr}$ (modificado de Elderfield 1986)

Variações na razão isotópica ${ }^{87} \mathrm{Sr} /{ }^{86} \mathrm{Sr}$ podem ser utilizadas para a obtenção de idades numéricas de carbonatos marinhos (Faure \& Mensing 2005). Esta técnica possibilita um meio de correlação para sedimentos marinhos em períodos de altas taxas de variação da composição isotópica de estrôncio dos oceanos (Oslick et al. 1994). A precisão alcançada com esse método chega a $\pm 0,3 \mathrm{Ma}$ (Katz et al. 2010). As idades baseadas nas razões isotópicas de estrôncio são calculadas a partir de equações que representam aproximações lineares válidas para faixas de idade pré-determinadas. Para a obtenção 
de idades numéricas de carbonatos marinhos são construídas curvas-padrão da razão isotópica de estrôncio para diferentes faixas de idade. Diversos autores propuseram curvas-padrão da razão ${ }^{87} \mathrm{Sr} /{ }^{86} \mathrm{Sr}$ dentre os quais Koepnick et al. (1985) para o Cenozoico, McArthur et al. (1993) para o Cretáceo Superior e Denison et al. (1997) para o Siluriano e Devoniano. Dados compilados a partir de diversas fontes e disponibilizados em publicações específicas, como no trabalho de Veizer et al. (1999), podem ser utilizados para construir trechos de uma curva-padrão de cunho global. A Figura 7 ilustra a curva global da razão isotópica ${ }^{87} \mathrm{Sr} /{ }^{86} \mathrm{Sr}$ apresentada em Elderfield (1986).

Os principais materiais utilizados para a cronometria de estrôncio são carapaças de belemnites ${ }^{12}$, conodontes $^{13}$ e testas de foraminíferos. Devido ao longo tempo de residência do estrôncio nos oceanos (2 a $4 \mathrm{Ma}$ ), misturas de foraminíferos planctônicos

\footnotetext{
${ }^{12}$ Cefalópodos que viveram entre 0 Carbonífero e 0 Cretáceo.

${ }^{13}$ Dentes ou peças denticuladas que compõem 0 aparelho alimentar de pequenos cordados em forma de enguia que viveram entre 0 Cambriano e 0 Triássico.
}

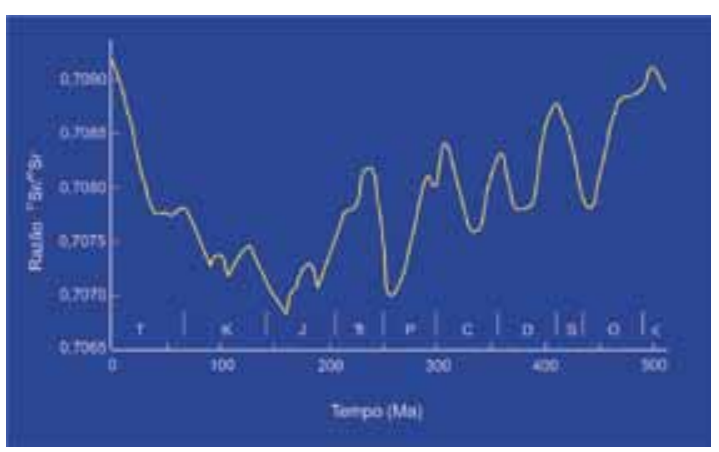

Figura 7. Curva global da razão ${ }^{87} \mathrm{Sr} /{ }^{86} \mathrm{Sr}$ (Modif. Faure, 2003). $T$ = Terciário; $K=$ Cretáceo; $J=$ Jurássico; $\mathrm{K}=$ Triássico; $\mathrm{P}=$ Permiano; $\mathrm{C}=$ Carbonífero; $\mathrm{D}=$ Devoniano; $\mathrm{S}=$ Siluriano; $\mathrm{O}=$ Ordoviciano; $\mathrm{E}=$ Cambriano

e bentônicos podem ser utilizadas como amostras unificadas sem incorrer em interferências relacionadas à diferença de habitat desses organismos (Katz et al. 2010).

Embora de reconhecida eficácia, a aplicação do método de datação por meio da razão isotópica de estrôncio apresenta limitações, dentre as quais a seleção de materiais para a realização das análises. Amostras alteradas por efeitos diagenéticos fornecem idades errôneas, uma vez que os mesmos atuam modificando a composição isotópica original de estrôncio (Holser et al. 1996). Durante a recristalização, o crescimento dos cristais de calcita se processa mais lentamente do que durante a precipitação biogênica, e em taxas de precipitação mais baixas a incorporação do estrôncio é menor.

Critérios mineralógicos e químicos são úteis para se evitar a utilização de materiais alterados em análises, buscando garantir que a composição isotópica das carapaças permanece inalterada mesmo em fósseis aparentemente bem preservados. Razões entre elementos químicos ou isotópos tais como $\mathrm{Mg} / \mathrm{Ca}, \mathrm{Sr} / \mathrm{Ca}$ ou ${ }^{13} \mathrm{C} /{ }^{12} \mathrm{C}$ e ${ }^{18} \mathrm{O} /{ }^{16} \mathrm{O}$, cujos valores variam em uma faixa estreita nos carbonatos marinhos de origem biogênica, são excelentes indicadores da preservação de microfósseis de parede calcária. Por exemplo, os valores da razão $\mathrm{Sr} / \mathrm{Ca}$ obtidos por diversos autores (e.g. Hampt \& Delaney 1997, Lea et al. 1999, Lear et al. 2003, Hall \& Chang 2004) em testas de foraminíferos datados do Eoceno ao Recente variaram de $0,71 \mathrm{mmol} /$ mol a 2,83 $\mathrm{mmol} / \mathrm{mol}$. Segundo Graham et al. (1982), valores da razão $\mathrm{Sr} / \mathrm{Ca}$ mais baixos do que o de amostras contemporâneas, associados a razões ${ }^{18} \mathrm{O} /{ }^{16} \mathrm{O}$ anormalmente baixas, são indicativos de recristalização.

Além da avaliação da composição, a utilização de técnicas de imageamento como a microscopia eletrônica de varredura permite identificar alterações de origem diagenéticas, já que, como todo carbonato de origem biogênica, a parede das testas dos foraminíferos apresentam estrutura sistemática cuja preservação é um dos fatores que podem atestar a integridade da amostra (Fig. 8).

\section{Métodos numéricos}

A composição das associações de foraminíferos planctônicos é extremamente sensível às propriedades das águas superficiais, especialmente a temperatura (Kucera et al. 2005). Além desse fator, a abundância de espécimes e a fácil separação das testas do sedimento fazem dos foraminíferos planctônicos organismos particularmente adequados para as análises quantitativas.

Os foraminíferos representam um dos grupos de microfósseis mais aplicados na obtenção de dados paleoambientais, fornecendo diversos indicadores desde assinaturas isotópicas até aspectos taxonômicos ecologicamente controlados, tais como morfologia das testas e a abundância dos táxons (Kucera et al. 2005).

A influência dos parâmetros ambientais nas testas dos foraminíferos planctônicos pode ser 


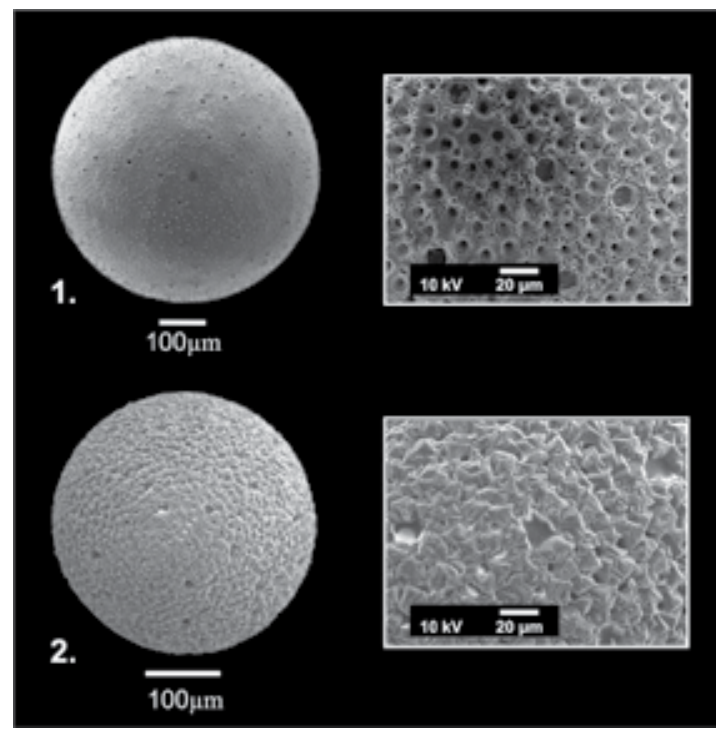

Figura 8. Estrutura da parede da espécie Orbulina universa. 1. espécime recente com sinais de dissolução; 2. espécime fóssil recristalizado

exemplificada por meio da variação do sentido do enrolamento das testas. Espécies portadoras de testas com arranjo trocoespira $1{ }^{14}$ podem apresentar enrolamento dextral (no sentido horário) ou sinistral (no sentido anti-horário). Algumas espécies apresentam preferência por um desses sentidos de enrolamento, enquanto outras exibem proporções variadas de mistura dos dois tipos (Fig. 9). Mudanças no sentido do enrolamento representam uma resposta ecofenotípica ${ }^{15}$, sobretudo variações da temperatura das águas superficiais (Kucera 2007).

Foi identificada uma relação consistente entre a direção do enrolamento e a temperatura das águas superficiais na espécie Neogloboquadrina pachyderma. Esta espécie habita as águas polares dos dois hemisférios, e se encontra ausente em massas d'água tropicais (Kucera 2007). Sua representatividade aumenta à medida que a temperatura decresce até alcançar $100 \%$ em águas com temperatura entre $10^{\circ} \mathrm{C}$ e o ponto de congelamento. Deste modo, a mudança no sentido do enrolamento dessa espécie pode ser utilizada como indicador paleoambiental. A proporção entre espécies de águas quentes e águas frias pode ser utilizada para traçar a história térmica da superfície do oceano tanto em nível de variações seculares quanto em escala de tempo geológico.

Com base no exemplo anterior percebe-se

\footnotetext{
${ }^{14}$ Arranjo no qual as câmaras estão dispostas em espiral.

${ }^{15}$ Modificação decorrente de variações nos parâmetros ambientais que afetam características morfológicas. Nos foraminíferos correspondem ao sentido do enrolamento e tamanho da testa.
}

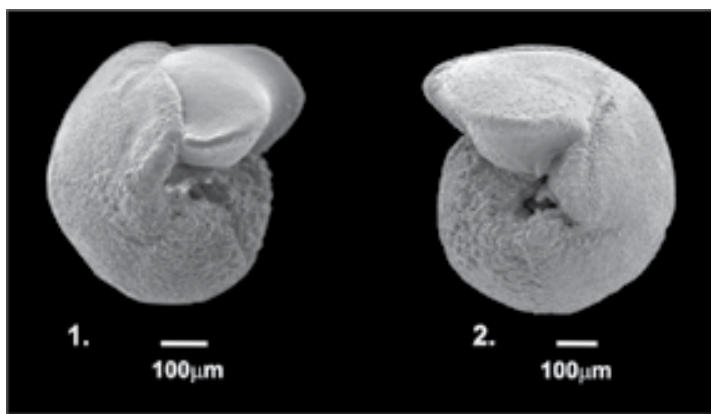

Figura 9. Espécimes de Globorotalia truncatulinoides com enrolamento sinistral (1) e dextral (2). O sentido do enrolamento é verificado com base no lado espiral da testa, com isso, do lado umbilical o enrolamento é invertido

que a relação entre as variáveis ambientais e as associações de foraminíferos planctônicos levou ao desenvolvimento de métodos quantitativos que, segundo Kucera (2007), evoluíram a partir da expressão matemática de relações ecológicas.

O entendimento da maioria dos processos oceanográficos requer o conhecimento de valores absolutos dos parâmetros ambientais. Para obter este tipo de dado, a quantificação das espécies e das associações representa um método simples e efetivo, mas a sua principal limitação está nas reconstruções qualitativas. Devido a isso, as abundâncias dos foraminíferos planctônicos passaram a ser calibradas empiricamente em função dos parâmetros ecológicos, constituindo as chamadas funções de transferência. As funções de transferência, introduzidas por Imbrie \& Kipp (1971), envolvem a análise matemática de associações fossilíferas para a reconstrução de parâmetros ambientais com base em associações recentes.

Segundo Kucera et al. (2005), o processo de calibração ecológica aplicado às funções de transferência com base em foraminíferos planctônicos consiste de três passos: (i) a contagem do número de espécimes dos diferentes táxons nos oceanos modernos e medição dos parâmetros ecológicos nas localidades de coleta; (ii) o desenvolvimento de um modelo matemático para caracterizar e descrever a relações entre as variáveis ambientais e os dados da contagem e, (iii) a aplicação do modelo matemático às amostras fósseis para produzir uma estimativa dos parâmetros ambientais.

De acordo com Kucera et al. (2005), um exemplo da transição entre a simples quantificação das espécies e as funções de transferência é o método do "ótimo de temperatura" de Berger (1969), que combinou análise ecológica intuitiva e formulação 
Tabela 2. Dados da contagem hipotética das espécies típicas de águas tropicais

(\%) formas tropicais

\begin{tabular}{c|c|c|c|c|c|c}
\hline Espécie & $\begin{array}{c}\text { Globorotalia } \\
\text { tumida }\end{array}$ & $\begin{array}{c}\text { Globigerina } \\
\text { calida }\end{array}$ & $\begin{array}{c}\text { Globigerinoides } \\
\text { ruber (var. rosea) }\end{array}$ & $\begin{array}{c}\text { Globorotalia } \\
\text { men ardii }\end{array}$ & $\begin{array}{c}\text { Globigerina } \\
\text { rubescens }\end{array}$ & Total \\
\hline Amostra \#01 & 6,6 & 5,0 & 9,1 & 12,0 & 3,4 & 36,1 \\
\hline Amostra \#02 & 1,2 & 1,2 & 9,0 & 2,3 & 1,5 & 15,1 \\
\hline Amostra \#03 & 4,8 & 5,5 & 9,7 & 16,8 & 1,9 & 38,8 \\
\hline
\end{tabular}

Tabela 3. Dados de contagem hipotética das espécies típicas de águas subtropicais

(\%) formas subtropicais

\begin{tabular}{c|c|c|c}
\hline Espécie & $\begin{array}{c}\text { Neogloboquadrina } \\
\text { Dutertrei (dex.) }\end{array}$ & $\begin{array}{c}\text { Globigerinoides } \\
\text { trilobus }\end{array}$ & Total \\
\hline Amostra \#01 & 16,0 & 28,6 & 44,6 \\
\hline Amostra \#02 & 0,2 & 10,0 & 10,2 \\
\hline Amostra \#03 & 18,8 & 26,7 & 45,5 \\
\hline
\end{tabular}

matemática, a qual foi expressa na equação abaixo:

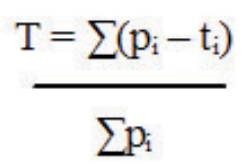

onde $\mathrm{p}_{\mathrm{i}}$ é a proporção e $\mathrm{t}_{\mathrm{i}}$ é a temperatura ótima para a espécie "i", a temperatura $\left(\mathrm{t}_{\mathrm{i}}\right)$ é dada pela distribuição das associações de foraminíferos dos oceanos modernos em amostras de fundo e representa um tipo de calibração empírica.

O método de calibração por meio da regressão multivariada se baseia na premissa de que a proporção das espécies típicas de diferentes massas d'água varia com a temperatura. Como as associações fossilíferas podem conter uma combinação de táxons que respondem a diferentes aspectos ambientais, deve-se atribuir pesos diferentes aos táxons de acordo com sua sensibilidade ambiental às variáveis que se deseja inferir (Guiot \& De Vernal 2007).

A equação abaixo simula uma calibração empírica para a determinação da temperatura:

$$
\mathrm{T}\left({ }^{\circ} \mathrm{C}\right)=\sum \mathrm{x}_{\mathrm{i}} \mathrm{n}_{\mathrm{i}}
$$

onde $\mathrm{x}_{\mathrm{i}}$ é proporção da espécie-índice e $\mathrm{n}_{\mathrm{i}}$ é o peso atribuído à espécie "i” na determinação da temperatura.

Como intuito de apresentar um exemplo de aplicação, com base na equação acima, tem-se o censo hipotético de três amostras, apresentado nas tabelas 2 a 5 , e, supondo-se que $\alpha=0,4 ; \beta=0,2$; $\phi=0,2$ e $\Delta=0,1$ é possível calcular a temperatura, cujos resultados estão listados na tabela 6 .

A partir das funções de transferência surgiu a técnica dos análogos modernos (Modern Analogue Techinique - MAT), a qual se baseia na comparação de associações de foraminíferos fósseis com associações recuperadas de amostras atuais.

As amostras atuais se constituem na base de comparação para a interpolação das condições paleoambientais com base nos análogos modernos, ou seja, a aplicação da técnica tem como objetivo encontrar amostras atuais que mais se assemelhem às amostras fósseis (Hutson 1979). Para tanto, existem bases de dados de amostras atuais coletadas em todos os oceanos em uma grande variedade de ambientes e latitudes. Cada amostra fóssil é comparada com todas as amostras da base de dados atuais, que representam o mesmo tipo de ambiente sedimentar das associações fósseis registradas localmente (Guiot \& De Vernal 2007).

A partir dos parâmetros ecológicos da associação recente e, assumindo-se que as exigências ecológicas das espécies permaneceram as mesmas ao longo dos últimos milhares de anos, é possível inferir os parâmetros ambientais para as associações fossilíferas. Além dos princípios do atualismo e do uniformitarismo ${ }^{16}$, esta técnica assume que associações florísticas e faunísticas se desenvolvem sob regimes climáticos similares.

${ }^{16}$ Princípios idealizados por James Hutton. 0 uniformitarismo sustenta que os processos geológicos são lentos e graduais. 0 atualismo é baseado na premissa de que o presente é a chave do passado, ou seja, o registro geológico é resultado de processos similares aos que se observam nos dias atuais. 
Tabela 4. Dados de contagem hipotética das espécies típicas de águas subpolares

\begin{tabular}{c|c|c|c}
\hline \multicolumn{4}{c}{ (\%) formas subpolares } \\
\hline Espécie & $\begin{array}{c}\text { Neogloboqua- } \\
\text { drina } \\
\text { pachyderma } \\
\text { (dex.) }\end{array}$ & $\begin{array}{c}\text { Globigeri- } \\
\text { na bulloides }\end{array}$ & Total \\
\hline Amostra \#01 & 5,3 & 12,2 & 17,5 \\
\hline Amostra \#02 & 13,6 & 14,5 & 28,1 \\
\hline Amostra \#03 & 7,1 & 7,2 & 14,3 \\
\hline
\end{tabular}

Tabela 5. Dados de contagem hipotética das espécies típicas de águas polares

\begin{tabular}{c|c|c|c}
\hline \multirow{4}{*}{ (\%) formas polares } \\
\hline Espécie & $\begin{array}{c}\text { Neogloboqua- } \\
\text { drinaw } \\
\text { pachyderma } \\
\text { (sin.) }\end{array}$ & $\begin{array}{c}\text { Globigerina } \\
\text { quinqueloba }\end{array}$ & Total \\
\hline Amostra \#01 & 0 & 1,8 & 1,8 \\
\hline Amostra \#02 & 38,1 & 8,5 & 46,6 \\
\hline Amostra \#03 & 0,2 & 1,2 & 1,4 \\
\hline
\end{tabular}

A importância da técnica dos análogos modernos reside no fato de que as condições oceanográficas obtidas a partir de análogos permitem estimar a salinidade e a temperatura das águas superficiais de oceanos pretéritos. São obtidos índices de dissimilaridade ${ }^{17}$ e valores do grau de confiabilidade de modo que é possível saber quais as amostras atuais que mais se parecem às amostras fósseis estudadas. O índice de dissimilaridade apresenta valores entre 0 e 1 , onde o zero representa similaridade total entre o análogo e a amostra estudada. São consideradas aceitáveis para as estimativas das variáveis ambientais os análogos com índice de até 0,2 .

Outras técnicas foram desenvolvidas, entre as quais o SIMMAX (sigla para "Técnica de Análogos Modernos Utilizando Índice de Similaridade”) de Pflaumann et al. (1996) e o Revised Analog Method (RAM) de Waelbroeck et al. (1998), que se constituem em variantes da MAT com poucas modificações. A técnica SIMMAX introduz um índice de similaridade, simplifica o número de espécies e apresenta algumas variações taxonômicas (Pflaumann et al. 1996).

Como a quantidade de dados requerida para aplicação das técnicas de análogos modernos é grande, se faz necessária a utilização de softwares. Um exemplo de recurso computacional para a reconstru-

\footnotetext{
${ }^{17}$ Medida da regularidade com que dois grupos estão distribuídos em áreas geográficas que compõem uma área maior. Também é utilizado como uma medida de desigualdade.
}

Tabela 6. Resultados do cálculo de temperatura obtidos a partir de dados hipotéticos

\begin{tabular}{c|c}
\hline Amostra & Temperatura $\left({ }^{\circ} \mathbf{C}\right)$ \\
\hline Amostra \#01 & 26,9 \\
\hline Amostra \#02 & 9,9 \\
\hline Amostra \#03 & 13,0 \\
\hline
\end{tabular}

ção paleoambiental por métodos análogos é o PaleoAnalogs, um software com base Java desenvolvido na Universidad de Salamanca para processar a Técnica dos Análogos Modernos (MAT).

O Paleoanalogs combina a Técnica dos Análogos Modernos com a análise interativa para produzir reconstruções rápidas e confiáveis de parâmetros ambientais como a temperatura da superfície do oceano (Théron et al. 2004). Para empregar essa ferramenta, disponível em http://paleosofttools. usal.es, o usuário deve possuir um censo dos táxons para uma ou mais amostras fósseis e uma base de dados contendo um ou mais conjuntos de amostras modernas com características similares.

\section{Considerações finais}

A paleoceanografia abrange uma variedade de temas de interesse para compreensão da evolução do planeta ao fornecer informações acerca da temperatura, produtividade e circulação de oceanos pretéritos. Ao lado da paleontologia e da paleogeografia, a paleoceanografia desempenha importante papel na reconstrução dos processos de abertura e fechamento de oceanos e do desenvolvimento da vida e distribuição dos organismos dos oceanos, além de proporcionar meios para efetuar prognósticos para o futuro.

Neste trabalho, procurou-se sintetizar os principais métodos de análise que fornecem subsídios à paleoceanografia utilizando foraminíferos planctônicos, organismos que estão entre os mais adequados às análises paleoceanográficas uma vez que ocorrem globalmente e muitas espécies refletem a composição isotópica da água do mar à época da formação de suas carapaças. Por sua vez, os métodos análogos utilizam a composição da amostra em termos de espécies para, por meio de comparação com análogos atuais, conhecer-se os parâmetros ambientais pretéritos. 
Pretende-se, com isto, apresentar as aplicações da ferramenta e mostrar a importância e a versatilidade dos foraminíferos planctônicos enquanto indicadores de processos de cunho global.

\section{Agradecimentos}

Os autores agradecem a Antônio Enrique Sanjinés (BPA/CENPES/Petrobras) e a Henrique Zerfass (ECT/UP/Petrobras) pela leitura crítica do manuscrito. A Seirin Shimabukuro e Elisabete Pedrão (BPA/CENPES/Petrobras) pelas excelentes sugestões. Aos gerentes Edison José Milani (PDEXP/Petrobras) e Oscar Strohschoen Jr. (BPA/ PDEXP/Petrobras) por terem autorizado a publicação. Ao Dr. Ismar de Souza Carvalho e a um revisor anônimo cujas sugestões muito contribuíram para enriquecer este trabalho.

\section{Referências bibliográficas}

Bemis B.E., Spero H.J., Bijma J., Lea D.W. 1998. Reevaluation of the oxygen isotopic composition of planktonic foraminifera: Experimental results and revised temperature equations. Paleoceanography, 13(2):150-160.

Berger W.H. 1969. Ecological patterns of living planktonic foraminífera. Deep-Sea Research, 16:124.

Bowen R. 1988. Isotopes in the Earth Sciences. Elsevier, Cambridge, 647p.

Denison R. E., Koepnick R. B., Burke W. H., Hetherington E. A., Fletcher A. 1997. Construction of the Silurian and Devonian ${ }^{87} \mathrm{Sr} /{ }^{86} \mathrm{Sr}$ curve. Chemical Geology, 140(1-2):109-121.

Elderfield H. 1986. Strontium isotope stratigraphy. Palaeogeography, Palaeoclimatology, Palaeoecology, 57(1):71-90.

Erez J. 1978. Vital effect on stable-isotope composition seen in foraminifera and coral skeletons. Nature, 273:199-202.

Faure G. 1986. Principles of Isotope Geology. John Wiley \& Sons, New York, 589p.

Faure G., Mensing T. M. 2005. Isotopes. Principles and applications. John Willey, New York. 897p.

Graham D. W., Bender M. L., Williams D. F., Keigwin L.D. 1982. Strontium-calcium ratios in Cenozoic planktonic foraminifera. Geochimica et Cosmochimica Acta, 46:1281-1292.

Grossman E.L. 1987. Stable isotope in modern benthic foraminifera: A study of vital effect. Journal of
Foraminiferal Research, 17(1):48-61.

Guiot J., De Vernal A. 2007. Transfer functions: methods for qualitative paleoceanography based on microfossils. In: C. Hillarie-Marcel \& A. De Vernal. eds. 2007. Developments in Marine Geology,Volume 1, Proxies in Late Cenozoic Paleoceanography, Elsevier. pp. 523-562.

Hampt G Delaney M.L. 1997 Influences on calcite $\mathrm{Sr} / \mathrm{Ca}$ records from Ceara Rise and other regions: distinguishing ocean history and calcite recrystallization. In: Shackleton N.J., Curry W.B., Richter C., Bralower T.J. eds. 1997. Proceedings of the Ocean Drilling, Scientific Results. College Station, TX (Ocean Drilling Program),v. 154, p. 491-500.

Hall J. M., Chang L.H. 2004. Li/Ca in multiple species of benthic and planktonic foraminifera: thermocline, latitudinal, and glacial-interglacial variation. Geoch. et Cosmoch. Acta, 68(3): 529-545.

Hay W.W. 1988. Paleoceanography: A review for the GSA Centennial. Geol. Soc. Am. Bull., 100:19341956.

Hoefs J. 2009. Stable isotope geochemistry. $6^{\text {th }}$ eds. Springer., 285p.

Holser W.T., Magaritz M., Ripperdan R.L. 1996. Global isotopic events. In: Walliser O.H. ed. Global events and event stratigraphy in the Phanerozoic. Berlin, Springer-Verslag. p. 63-68.

Hughen K.A. 2007. Radiocarbon dating of deep-sea sediments. In: Hillaire-Marcel C. \& De Vernal, A. eds. 2007. Proxies in Late Cenozoic Paleoceanography; Developments in Marine Geology. p. 185-210.

Hutson W.H. 1979. The Agulhas Current during the Late Pleistocene: Analysis of modern faunal analogs. Science, 207:64-66.

Imbrie J., Kipp N.G. 1971. A new micropaleontological method for quantitative paleoclimatology: Application to a late Pleistocene Caribbean core. In: Turekian K.K., ed.. The Late Cenozoic Glacial Ages. Yale University Press, New Haven. p. 71-181.

Katz M.E., Cramer B.S., Franzese A., Hönisch B., Miller K., Rosenthal Y. \& Wright J.D. 2010. Traditional and emerging geochemical proxies in foraminifera. Journal of Foraminiferal Research, 40(2):165-192.

Koepnick R.B., Burke W.H., Denison R.E., Hetherington E.A., Nelson H.F., Otto J.B., Waite L.E. 1985. Construction of the seawater [87] Sr/ [86]Sr curve for the Cenozoic and Cretaceous: Supporting data. Chemical Geology, 58(1-2):55-81.

Kucera M. 2007. Planktonic foraminifera as tracers of past oceanic environments. In: C. HillarieMarcel \& A. De Vernal eds.. 2007. Developments in Marine Geology Volume 1, Proxies in Late Cenozoic 
Paleoceanography. Elsevier. p. 213-262.

Kucera M., Weinelt M., Kiefer T., Pflaumann U., Hayes A., Weinelt M., Chen M.-T., Mix A., Barrows T.T., Cortijo E., Duprat J., Juggins S., Waelbroeck C. 2005. Reconstruction of sea-surface temperature from assemblages of planktonic foraminifera: multi-technique approach based on geographically constrained calibration data sets and its application to glacial Atlantic and Pacific Oceans. Quaternary Science Reviews, 24:951-998.

Lea D. W., Mashiotta T. A., Spero H. 1999. Controls on magnesium and strontium uptake in planktonic foraminifera determined by live culturing. Geoch. et Cosmoch. Acta, 63(16):2369-2379.

Lear C.H., Elder H., Wilson P.A. 2003. A Cenozoic seawater $\mathrm{Sr} / \mathrm{Ca}$ record from benthic foraminiferal calcite and its application in determining global weathering fluxes. Earth Planet. Sci. Letters, 208:6984

Libby W.F. 1970. Radiocarbon dating. Phil. Trans. Royal Society of London A., 269:1-10.

Loeblich A.R., Tappan H. 1992. Present status of foraminiferal classification, in Studies in Benthic Foraminifera. In: Y. Takayanagi \& T. Saito. eds. Proceedings of the Fourth International Symposium on Benthic Foraminifera, Sendai, 1990 (Benthos 90). Tokai University Press, Tokyo, Japan, p. 93-102.

McArthur J.M., Thirlwall M.F., Gale.A.S, Chen M., Kennedy W.J. 1993. Strontium isotope stratigraphy in the Late Cretaceous: numerical calibration of the $\mathrm{Sr}$ isotope curve and intercontinental correlation for the Campanian. Paleoceanography, 8:859-873.

Mitchell S.F., Paul C.R.C., Gale A.S. 1996. Carbon isotopes and sequence stratigraphy. In: Howell, J.A. \& Aitken, J.F. eds.. High resolution sequence stratigraphy: innovations and applications. Geological Society Special Publication, 104:11-24.

Oslick J.S., Miller K.G., Feigenson M.D. 1994. Oligocene-Miocene strontium isotopes: Stratigraphic revisions and correlations to an inferred galcioeustatic record. Paleoceanography, 9(3):427-443.

Pflaumann U., Duprat J., Pujol C., Labeyirie L. 1996. SIMMAX: A modern analogue technique to deduce Atlantic sea surface temperature from planktonic foraminifera in deep-sea sediments. Paleoceanography, 11:15-35.

Ravelo A.C., Hillaire-Marcel C. 2007. The use of oxygen and carbon isotopes of foraminifera in paleoceanography. In:Hillaire-Marcel, C. \& De Vernal A. 2007. Proxies in late Cenozoic paleoceanography. Developments in Marine Geology, 1. Elsevier. p. 735-764.

Schackleton N.J. 1987. Oxygen isotopes, ice volume and sea level. Quaternary Science Reviews, 6:183190.

Scholle P. A. \& Arthur M.A. 1980. Carbon isotope fluctuations in cretaceous pelagic limestones: potential stratigraphic and petroleum exploration tool. Ame. Assoc. Petrol. Geol. Bull., 64(1):67-87.

Scott G.H. 1983. Biostratigraphy and histories of upper Miocene-Pliocene Globorotalia, South Atlantic and South West Pacific. Marine Micropaleontology, 7:369-383.

Sen Gupta B.K. 1999. Systematics of Modern Foraminifera. In: Sen Gupta, B.K. ed., Modern Foraminifera. Kluwer Acad. Publ., p. 7-36.

Schiebel R., Hemblen C. 2005. Modern planktic foraminifera. Paläontologische Zeitschrift, 79(1):135148.

Spezzaferri S., Spiegler D. 2005. Fossil planktic foraminfera (an overview). Paläontologische Zeitschrift, 79(1):149-166.

Therón R., Paillard D., Cortijo E., Flores J.A., Sierro F.J., Waelbroeck C. 2004. Rapid reconstruction of paleoenvironmental features using a new multiplatform program. Micropaleontology, 50(4):391-395.

Veizer J., Ala D., Azmy K., Bruckschen P., Bruhn F., Buhl D., Carden G., Diener A., Ebneth S., Goddris Y., Jasper T., Korte C., Pawellek F., Podlaha O. \& Strauss H. $1999 .{ }^{87} \mathrm{Sr} /{ }^{86} \mathrm{Sr}, \delta^{18} \mathrm{O}$ and $\delta^{13} \mathrm{C}$ Evolution of Phanerozoic Seawater. Chemical Geology, 161:59-88.

Waelbroeck C., Labryrie L., Duplessy J.-C., Guiot J., Labracherie M., Leclaire M., Duprat J. 1998. Improving past sea surface temperature estimates based on planktonic fossils fauna. Paleoceanography, 13:272-283.

Wade M. 1964. Application of the lineage concept to biostratigraphic zoning based on planktonic foraminifera. Micropaleontology, 10(3):273-290.

Wefer G., Berger W.H., Bijma J., Fisher G. 1999. Clues to ocean history: A brief overview of proxies. In: Fisher, G. \& Wefer, G. eds.. Use of proxies in paleoceanography: Examples from South Atlantic. Springer-Verlag, Berlin, Heidelberg. p. 1-68.

Walker M. 2005. Quaternary dating methods. John Wilwy \& Sons, 286p. 